\title{
Catalpa seed oil rich in $9 t, 11 t, 13 c$-conjugated linolenic acid suppresses the development of colonic aberrant crypt foci induced by azoxymethane in rats
}

\author{
RIKAKO SUZUKI ${ }^{1}$, YUMIKO YASUI ${ }^{2}$, HIROYUKI KOHNO ${ }^{1}$, SHINGO MIYAMOTO ${ }^{1,3}$, \\ MASASHI HOSOKAWA ${ }^{2}$, KAZUO MIYASHITA ${ }^{2}$ and TAKUJI TANAKA ${ }^{1}$ \\ ${ }^{1}$ Department of Oncologic Pathology, Kanazawa Medical University, 1-1 Daigaku, Uchinada, Ishikawa 920-0293; \\ ${ }^{2}$ Graduate School of Fisheries Sciences, Hokkaido University, 3-1-1 Minato, Hakodate, Hokkaido 041-8611; \\ ${ }^{3}$ Division of Food Science and Biotechnology, Graduate School of Agriculture, Kyoto University, Kyoto 606-8502, Japan
}

Received May 3, 2006; Accepted June 2, 2006

\begin{abstract}
Catalpa (Catalpa ovata) seed oil (CPO) is a unique oil that contains a high amount of 9 trans, 11 trans, 13 cisconjugated linolenic acid. In the present study, we investigated whether dietary administration with $\mathrm{CPO}$ affects the development of azoxymethane (AOM)-induced colonic aberrant crypt foci (ACF) in male F344 rats to elucidate its possible cancer chemopreventive efficiency. Also, the effect of CPO on the fatty acid composition of liver tissue and colonic mucosa, the serum levels of total cholesterol and triglyceride, and the mRNA expression of cyclooxygenase (COX)-2 in the colonic mucosa were measured. In addition, the cell proliferation activity and apoptotic index in the colonic mucosa were estimated immunohistochemically. Animals were given two weekly subcutaneous injections of AOM $(20 \mathrm{mg} / \mathrm{kg}$ body weight). They also received the experimental diet containing $0.01 \%, 0.1 \%$ or $1 \% \mathrm{CPO}$ for 4 weeks, starting one week before the first dosing of AOM. AOM exposure produced a substantial number of ACF $(99 \pm 28)$ at the end of the study (week 4). Dietary administration of $\mathrm{CPO}$ reduced the number of $\mathrm{ACF}(\mathrm{AOM}+0.01 \% \mathrm{CPO}, 32 \pm 11, \mathrm{P}<0.001 ; \mathrm{AOM}+0.1 \%$ $\mathrm{CPO}, 35 \pm 18, \mathrm{P}<0.001 ; \mathrm{AOM}+1 \% \mathrm{CPO}, 18 \pm 10, \mathrm{P}<0.001)$. $9 t, 11 t$-conjugated linoleic acid was detected in the liver tissue and colonic mucosa of rats fed the CPO-containing diet. Additionally, dietary administration with CPO decreased the serum triglyceride level and the expression of COX-2 mRNA in the colonic mucosa. The indices of cell proliferation and apoptosis in the colonic mucosa of rats treated with AOM and $1 \%$ CPO have significant differences when compared with the AOM alone group. These findings suggest the possible chemo-
\end{abstract}

Correspondence to: Dr Takuji Tanaka, Department of Oncologic Pathology, Kanazawa Medical University, 1-1 Daigaku, Uchinada, Ishikawa 920-0293, Japan

E-mail: takutt@kanazawa-med.ac.jp

Key words: catalpa seed oil, conjugated linolenic acid, aberrant crypt foci, inhibition, rat, colon preventive activity of CPO in the early phase of colon carcinogenesis.

\section{Introduction}

Colon cancer is one of the leading causes of cancer deaths in Asia and Western countries $(1,2)$. Therefore, it is a major public health problem around the world. Dietary factors, including a high fat content, influence colon cancer development $(1,2)$. Intake of $n-3$ polyunsaturated fatty acid (PUFA) is reported to prevent colorectal carcinogenesis $(3,4)$, while excessive consumption of n-6 PUFA or saturated fatty acids could promote colon cancer development (5). The type of dietary fat consumption is thus important for development of colonic malignancy.

Recently, conjugated fatty acids (CFAs) have received a great deal of attention because of their numerous beneficial biological effects including cancer preventive property (6-8). CFAs refer to a group of positional and geometric isomers of PUFAs containing conjugated double bonds. One of the CFAs, conjugated linoleic acid (CLA), is well-known for its biological effects. Regarding the inhibitory effect of cancer, CLA can inhibit chemically-induced skin, mammary, forestomach, and colon tumorigenesis in rodents (9-12). Although CLA is present in certain foods such as milk fat and meats derived from ruminant animals, the content is less than $1 \%$ (13).

On the other hand, some plant seed oils contain a large amount of conjugated linolenic acid (CLN), $\alpha$-Eleostearic acid $(9 c, 11 t, 13 t$-CLN) in tung and bitter melon seed oil (BMO) are present at $67.7 \%$ and $56.2 \%$, respectively (14). The seed oils of pomegranate, catalpa, and pot marigold contain $83.0 \%$ punicic acid $(9 c, 11 t, 13 c$-CLN), $42.3 \%$ catalpic acid $(9 t, 11 t, 13 c-C L N)$, and $62.2 \%$ calendic acid $(8 t, 10 t, 12 c-$ CLN), respectively (14). As for the biological activity of CLN, dietary CLN produced by alkaline isomerization of linolenic acid (LN) reduces fat content in the body (15). Purified punicic acid has a hypolipidemic effect (16). Additionally the antiobese property of pomegranate seed oil (PGO) has been reported. (17). Also we and other researchers have shown the cytotoxic effect of PGO and tung oil on a variety of human cancer cell lines, including colon cancer cells $(18,19)$. 
Table I. Fatty acid composition of CPO.

Fatty acid (wt $\%)$

\begin{tabular}{lr}
\hline $16: 0$ & 2.8 \\
$18: 0$ & 2.2 \\
$18: 1 \mathrm{n}-9$ & 7.6 \\
$18: 2 \mathrm{n}-6$ & 42.5 \\
$18: 3 \mathrm{n}-3$ & 0.6 \\
$9 c, 11 t, 13 c-\mathrm{CLN}$ & 0.1 \\
$9 c, 11 t, 13 t$-CLN & 0.1 \\
$9 t, 11 t, 13 c$-CLN & 40.2 \\
Others & 3.9 \\
\hline
\end{tabular}

Regarding the in vivo studies, CLN derived from perilla oil suppresses chemically-induced mammary adenocarcinomas in rats (10). We also found that dietary BMO inhibits the development of aberrant crypt foci (ACF) (20) that are precursor lesions of colon cancer (21). In addition, our recent studies demonstrated that BMO and PGO suppressed azoxymethane (AOM)-induced colon carcinogenesis in rats $(12,22)$. Regarding catalpa seed oil (CPO), we reported the cytotoxic effect of CPO on SV40-transformed Balb 3T3 A31 and human monocytic leukemia cell lines (18), but there are no in vivo studies on the effect of CPO on carcinogenesis.

In the present study, we investigated the influence of $\mathrm{CPO}$ in the development of AOM-induced ACF to elucidate the modifying effect of $\mathrm{CPO}$ on rat colon carcinogenesis. Additionally, we analyzed the lipid composition of liver tissue and colonic mucosa and measured the serum concentrations of total cholesterol and triglyceride to understand the possible mechanisms by which CPO could modify the occurrence of the lesions. Since overexpression of cyclooxygenase-2 (COX-2) is involved in colon carcinogenesis and certain cyclooxygenase inhibitors are likely to be useful as colon cancer chemopreventive agents (23-26), the effects of CPO on the expression of COX-2 in the non-lesional colonic mucosa were investigated. Also, biomarkers such as proliferating cell nuclear antigen (PCNA)-labeling index and apoptotic index were measured immunohistochemically in colonic mucosa, since $\mathrm{BMO}$ exerted an inhibitory effect on $\mathrm{ACF}$ via reduction of the PCNA index and induction of apoptosis in our previous study (20).

\section{Materials and methods}

Animals, chemicals, and diets. Male F344 rats (Charles River Japan, Inc., Tokyo, Japan) aged 4 weeks were used. The animals were maintained at Kanazawa Medical University Animal Facility according to the Institutional Animal Care Guidelines. They were housed in plastic cages (4 rats/cage) with free access to tap water and diet, under controlled conditions of humidity $(50 \pm 10 \%)$, lighting (12-h light/dark cycle), and temperature $\left(23 \pm 2^{\circ} \mathrm{C}\right)$. They were quarantined for 7 days and randomized by body weight into experimental and control groups. AOM for ACF induction was purchased from Sigma Chemical Co. (St. Louis, MO, USA). AIN-76A diet

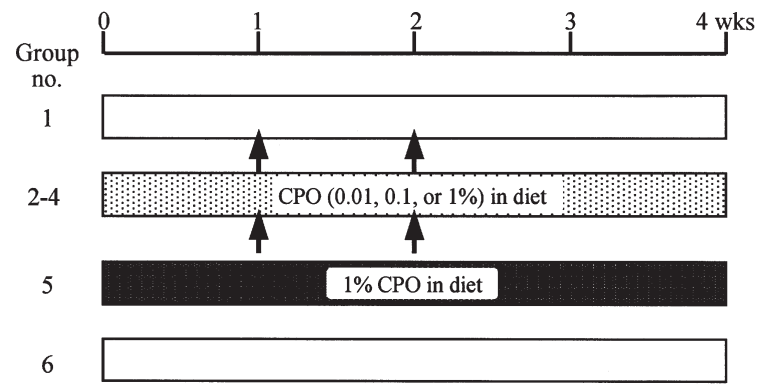

Figure 1. Experimental protocol. White bar, basal diet; dotted bar, CPO (0.01, 0.1, and 1\%); dashed bar, CPO $1 \%$; arrow, AOM, $20 \mathrm{mg} / \mathrm{kg}$ bw s.c.

(LSG Corporation, Tokyo, Japan) was used as basal diet throughout the study. Seeds of catalpa (Catalpa ovata) were kindly donated from Tohoku Seed Co. (Tochigi, Japan). Seed oil was extracted by $n$-hexane after crushing with an electric mill. Determination of fatty acid profile of the total lipids in CPO (Table I) was carried out according to the methods described previously (20).

Experimental procedure. A total of 40 male F344 rats were divided into five experimental groups and a control group (Fig. 1). Animals in groups 1 through 4 were initiated with AOM by two weekly subcutaneous injections $(20 \mathrm{mg} / \mathrm{kg}$ body weight). Rats in groups 1 and 6 were fed the basal diet containing 5\% corn oil. The diets for groups 2 and 3 were replaced by $0.01 \%$ and $0.1 \% \mathrm{CPO}$ in the $5 \%$ corn oil, respectively. Groups 4 and 5 were given the diet containing $1 \%$ CPO and $4 \%$ corn oil. These diets were given to rats for 4 weeks, starting one week before the first dosing of AOM. All rats were freely available for diet and tap water. All experimental diets containing $\mathrm{CPO}$ were prepared weekly in our laboratory and stored at $-20^{\circ} \mathrm{C}$ under a nitrogen atmosphere in airtight containers for no longer than a week. Rats were provided with the diet every day and the peroxide value of the lipids in the fresh diets was less than $3.0 \mathrm{meq} / \mathrm{kg}$ lipid. The rats were sacrificed under ether anesthesia at week 4 and underwent careful necropsy, with emphasis on the colon, liver, kidney, lung, and heart. The colons of five rats each from groups 1 through 4 and those of two rats each from groups 5 and 6 were fixed in $10 \%$ buffered formalin for assessing the occurrence of colonic ACF. The colons of the remaining rats were used for determining the expression of COX-2 protein and lipid analysis in colonic mucosa. The liver was weighed and the caudate lobe was removed and fixed in $10 \%$ buffered formalin for histological examination. Remaining lobes of the livers of all rats were used for analyses of fatty acid composition. All other tissues were fixed in $10 \%$ buffered formalin and submitted to histological examination.

Determination of ACF. The presence of ACF was determined according to the standard procedures that are routinely used in our laboratory (27). At necropsy, the colons were flushed with saline, excised, cut open longitudinally along the main axis, and then washed with saline. They were cut, placed on the filter paper, with their mucosal surface up, and then fixed in $10 \%$ buffered formalin for at least $24 \mathrm{~h}$. Fixed colons were stained with methylene blue $(0.5 \%$ in distilled water) for 
Table II. Body, liver, and relative liver weights in each group.

\begin{tabular}{llccc}
\hline Group no. & $\begin{array}{c}\text { Treatment } \\
\text { (no. of rats examined) }\end{array}$ & $\begin{array}{c}\text { Body weight } \\
(\mathrm{g})\end{array}$ & $\begin{array}{c}\text { Liver weight } \\
(\mathrm{g})\end{array}$ & $\begin{array}{c}\text { Relative liver weight } \\
(\mathrm{g} / 100 \mathrm{~g} \text { body weight) }\end{array}$ \\
\hline 1 & AOM alone (8) & $209 \pm 11^{\mathrm{a}}$ & $8.4 \pm 0.7$ & $4.03 \pm 0.33$ \\
2 & $\mathrm{AOM}+0.01 \%$ CPO (8) & $198 \pm 5$ & $7.2 \pm 0.7$ & $3.61 \pm 0.38$ \\
3 & $\mathrm{AOM}+0.1 \%$ CPO (8) & $197 \pm 13$ & $6.9 \pm 0.9^{\mathrm{b}}$ & $3.51 \pm 0.24$ \\
4 & AOM + 1\% CPO (8) & $203 \pm 10$ & $8.4 \pm 1.3$ & $4.12 \pm 0.46$ \\
5 & $1 \%$ CPO (4) & $204 \pm 8$ & $7.8 \pm 0.5$ & $3.80 \pm 0.30$ \\
6 & No treatment (4) & $199 \pm 11$ & $8.5 \pm 1.3$ & $4.25 \pm 0.46$ \\
\hline
\end{tabular}

${ }^{\mathrm{a}}$ Mean $\pm \mathrm{SD}$. ${ }^{\mathrm{b} S i g n i f i c a n t l y ~ d i f f e r e n t ~ f r o m ~ g r o u p ~} 1$ by Bonferroni Multiple Comparisons test $(\mathrm{P}<0.05)$.

$20 \mathrm{sec}$, dipped in distilled water, and placed on a microscope slide for counting ACF.

Lipid extraction and analysis. Tissue lipids were extracted by the Folch method using chloroform/methanol $(2: 1, \mathrm{v} / \mathrm{v})(28)$. Fatty acid methyl esters were prepared according to the method by Prevot and Mordret (29). Fatty acid methyl esters were analyzed by GC-FID (SHIMADZU GC-14B gas chromatograph, Shimadzu Seisakusho Co., Ltd., Kyoto, Japan) equipped with an Omegawax 320 capillary column (30 m x $0.32 \mathrm{~mm}$ I.D.). Peaks were identified by comparison with fatty acid standards (Nu-chek-Prep, MN, USA), and area and its percentage for each resolved peak were analyzed using Shimadzu Chromatopac C-R3A integrator (Shimadzu Seisakusho Co., Ltd.). The identification of CLA and/or CLN isomers was confirmed using GC-mass spectrometry after conversion of the methyl esters to dimethyloxazoline derivatives (30).

Measurements for the level of serum cholesterol and triglyceride. Serum cholesterol and triglyceride levels in rats were measured by enzymatic method using an Ekudia-L-Eiken kit according to the manufacturer's protocol (Eiken Chemical Co., Ltd., Tokyo, Japan).

Determination of COX-2 mRNA level in colonic mucosa by real-time PCR. For quantitative real-time PCR, total RNA was extracted from colonic mucosa using a Qiagen RNeasy mini kit (Qiagen, CA, USA) after homogenization using a QiAshredder column (Qiagen), and stored at $-80^{\circ} \mathrm{C}$. Total RNA was reverse transcribed by the High Capacity cDNA Archive kit (Applied Biosystems, CA, USA). cDNA was subjected to quantitative real-time PCR using TaqMan gene expression assay (Applied Biosystems) and TaqMan Universal PCR Master Mix (Applied Biosystems). An ABI PRISM 7000 system (Applied Biosystems) was used for the reaction and detection of the expression of COX-2 and B-actin mRNA. PCR amplification was performed in a total volume of $25 \mu \mathrm{l}$ containing $11.25 \mu \mathrm{l}$ cDNA template, $12.5 \mu \mathrm{l}$ of $2 \mathrm{X}$ TaqMan Universal PCR Master Mix, and $1.25 \mu 1$ of 20X TaqMan gene expression assay. For each reaction the AmpErase UNG and AmpliTaq Gold Enzyme were activated at $50^{\circ} \mathrm{C}$ for $2 \mathrm{~min}$ and $95^{\circ} \mathrm{C}$ for $10 \mathrm{~min}$, respectively. Amplification was then performed by 40 cycles of $95^{\circ} \mathrm{C}$ for $15 \mathrm{sec}$ and $60^{\circ} \mathrm{C}$ for $1 \mathrm{~min}$.
Immunohistochemistry. Immunohistochemistry for the PCNA and apoptotic nuclei was performed on $4-\mu \mathrm{m}$-thick paraffinembedded sections from colons of rats in each group by the labeled streptavidin biotin method using a LSAB KIT (Dako Japan, Kyoto, Japan) with microwave accentuation. The paraffin-embedded sections were heated for $30 \mathrm{~min}$ at $65^{\circ} \mathrm{C}$, deparaffinized in xylene, and rehydrated through graded ethanol at room temperature. A 0.05-M Tris $\mathrm{HCl}$ buffer ( $\mathrm{pH}$ 7.6) was used to prepare solutions and for washes between various steps. Incubations were performed in a humidified chamber. For the determination of PCNA-incorporated nuclei, PCNA-immunohistochemistry was performed according to the method described by Watanabe et al (31). Apoptotic index was also evaluated by immunohistochemistry for singlestranded DNA (ssDNA) (31). Sections were treated for $40 \mathrm{~min}$ at room temperature with $2 \%$ BSA and incubated overnight at $4^{\circ} \mathrm{C}$ with primary antibodies. Primary antibodies included anti-PCNA mouse monoclonal antibody (diluted 1:50; PC10, Dako Japan) and anti-ssDNA rabbit polyclonal antibody (diluted 1:300, Dako Japan). Horseradish peroxidase activity was visualized by treatment with $\mathrm{H}_{2} \mathrm{O}_{2}$ and 3,3'-diaminobenzidine for $5 \mathrm{~min}$. At the last step, the sections were weakly counterstained with Mayer's hematoxylin (Merck Ltd., Tokyo, Japan). For each case, negative controls were performed on serial sections. On the control sections, incubation with the primary antibodies was omitted. Intensity and localization of immunoreactivities against two primary antibodies used were examined on all sections using a microscope (Olympus BX41, Olympus Optical Co., Ltd., Tokyo, Japan). The PCNA and apoptotic indices were determined by counting the number of positive cells among at least 200 cells in the lesion, and were indicated as percentages.

Statistical evaluation. Where applicable, data were analyzed using one-way ANOVA with Bonferroni correction test with $\mathrm{P}<0.05$ as the criterion of significance.

\section{Results}

General observation. Body, liver, and relative liver weights ( $\mathrm{g} / 100 \mathrm{~g}$ body weight) in all groups are shown in Table II. All animals remained healthy throughout the experimental period. Food consumption (g/day/rat) did not differ significantly among the groups (data not shown). At the end of the study, 

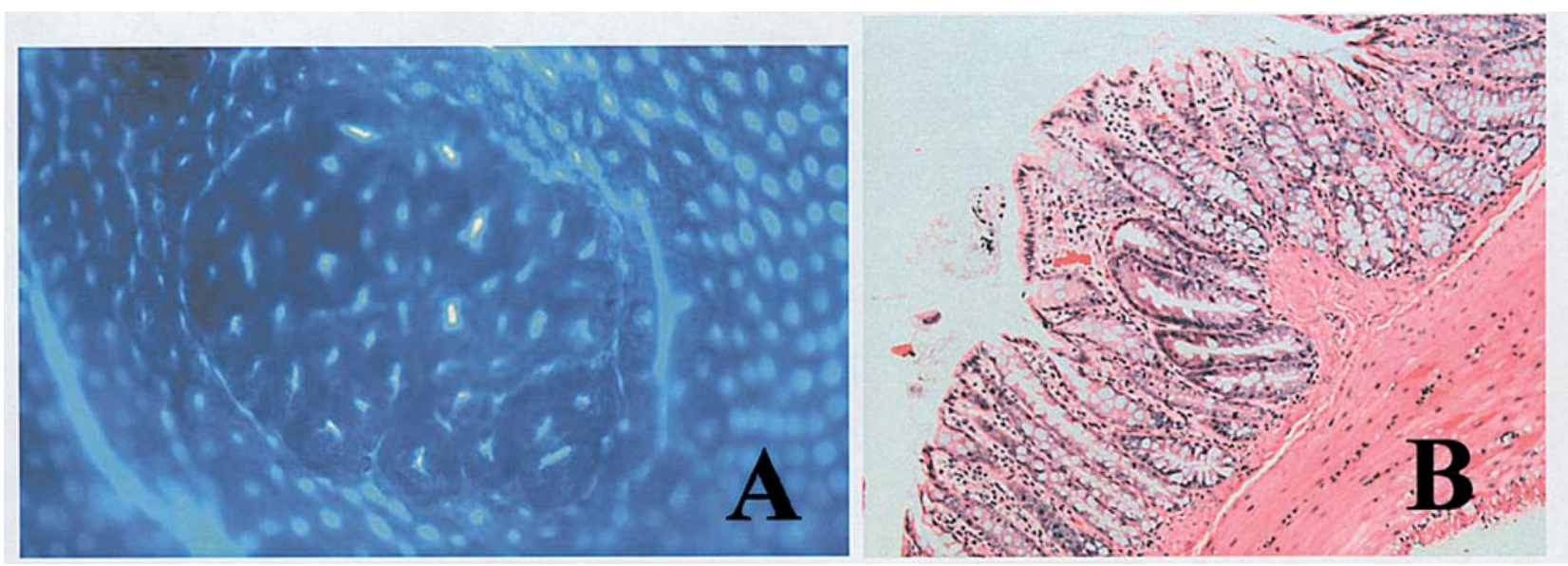

Figure 2. Morphology of representative ACF found in a rat from group 1. (A) ACF on methylene-blue-stained colonic mucosa; and (B) ACF on hematoxylin and eosin-stained section. Original magnification, (A) x4; and (B) x10.

Table III. Effect of CPO on AOM-induced ACF formation in male F344 rats.

\begin{tabular}{llcccc}
\hline Group no. & \multicolumn{1}{c}{$\begin{array}{c}\text { Treatment } \\
\text { (no. of rats examined) }\end{array}$} & No. of ACF/colon & No. of ACs/colon & No. of ACs/focus & $\begin{array}{c}\text { \% of ACF containing } \\
4 \text { or more ACs }\end{array}$ \\
\hline 1 & AOM alone (5) & $99 \pm 28^{\mathrm{a}}$ & $295 \pm 66$ & $3.01 \pm 0.20$ & $32.13 \pm 4.28$ \\
2 & AOM + 0.01\% CPO (5) & $32 \pm 11^{\mathrm{b}}$ & $50 \pm 17^{\mathrm{b}}$ & $1.57 \pm 0.10^{\mathrm{b}}$ & $1.25 \pm 2.80^{\mathrm{b}}$ \\
3 & AOM + 0.1\% CPO (5) & $35 \pm 18^{\mathrm{b}}$ & $60 \pm 35^{\mathrm{b}}$ & $1.70 \pm 0.21^{\mathrm{b}}$ & $1.30 \pm 1.78^{\mathrm{b}}$ \\
4 & AOM + 1\% CPO (5) & $18 \pm 10^{\mathrm{b}}$ & $32 \pm 18^{\mathrm{b}}$ & $1.80 \pm 0.15^{\mathrm{b}}$ & $1.62 \pm 2.25^{\mathrm{b}}$ \\
5 & $1 \%$ CPO (2) & 0 & 0 & 0 & 0 \\
6 & No treatment (2) & 0 & 0 & 0 & 0 \\
\hline
\end{tabular}

${ }^{\mathrm{a}}$ Mean $\pm \mathrm{SD} .{ }^{\mathrm{b}}$ Significantly different from group 1 by Bonferroni Multiple Comparisons test $(\mathrm{P}<0.001)$.

$\mathbf{A}$

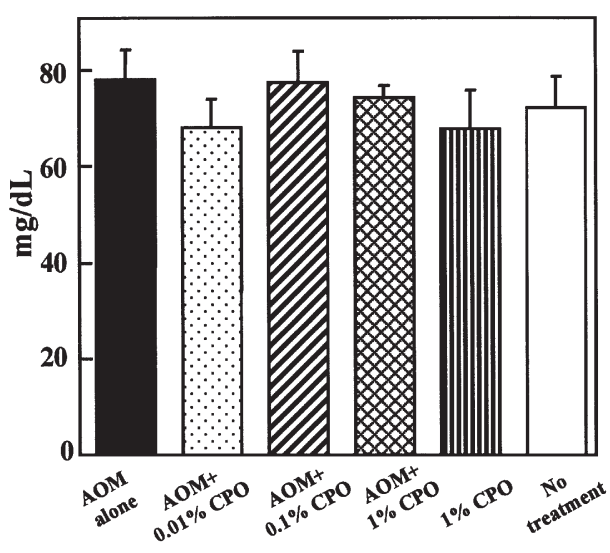

B

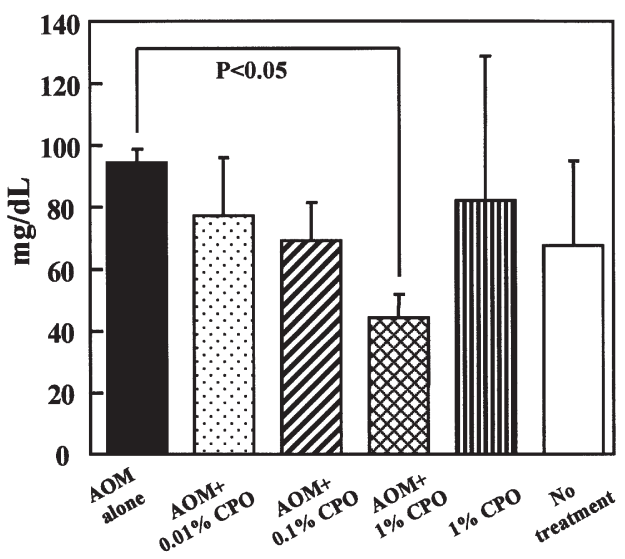

Figure 3. Effect of CPO on total cholesterol and triglyceride in serum. (A) Total cholesterol level, (B) triglyceride level.

there were no significant differences in the mean body weight among the groups. Although the liver weight of group 3 was statistically lower than that of group $1(\mathrm{P}<0.05)$, the mean relative liver weights did not show significant differences among the groups.
ACF analysis. The data on colonic ACF (Fig. 2) formation are summarized in Table III. All rats belonging to groups 1 through 4, which were given AOM, developed ACF. When compared to the mean number of $\mathrm{ACF} /$ colon in group 1 (AOM alone, $99 \pm 28$ ), the dietary administration of $0.01 \%$ 
Table IV. Effect of CPO diets on fatty acid composition of liver lipids.

\begin{tabular}{|c|c|c|c|c|c|c|c|c|c|c|c|c|}
\hline \multirow{2}{*}{$\begin{array}{l}\text { Group } \\
\text { no. }\end{array}$} & \multirow{2}{*}{$\begin{array}{c}\text { Treatment } \\
\text { (no. of rats examined) }\end{array}$} & \multicolumn{11}{|c|}{ Fatty acid (wt\%) } \\
\hline & & $16: 0$ & $16: 1 \mathrm{n}-7$ & $18: 0$ & $18: 1 \mathrm{n}-9$ & $18: 1 \mathrm{n}-7$ & $18: 2 n-6$ & $20: 4 n-6$ & $22: 5 n-6$ & $22: 6 n-3$ & $9 c, 11 t$-CLA & $9 t, 11 t$-CLA \\
\hline 1 & $\begin{array}{l}\text { AOM alone } \\
\quad(8)\end{array}$ & $23.6 \pm 0.8^{\mathrm{a}}$ & $5.7 \pm 1.1$ & $13.6 \pm 1.2$ & $13.9 \pm 2.5$ & $5.8 \pm 0.2$ & $10.8 \pm 1.4$ & $17.3 \pm 1.4$ & $1.3 \pm 0.1$ & $2.5 \pm 0.4$ & N.D. & N.D. \\
\hline 2 & $\begin{array}{c}\mathrm{AOM}+0.01 \% \mathrm{CPO} \\
(8)\end{array}$ & $24.1 \pm 1.7$ & $5.2 \pm 1.3$ & $12.6 \pm 1.3$ & $15.7 \pm 2.3$ & $4.5 \pm 0.5$ & $11.4 \pm 1.6$ & $17.1 \pm 2.3$ & $0.9 \pm 0.1$ & $3.1 \pm 0.5$ & $0.01 \pm 0.0$ & $0.05 \pm 0.0$ \\
\hline 3 & $\begin{array}{c}\mathrm{AOM}+0.1 \% \mathrm{CPO} \\
(8)\end{array}$ & $23.7 \pm 1.6$ & $5.4 \pm 1.3$ & $13.2 \pm 1.5$ & $15.2 \pm 2.3$ & $4.9 \pm 0.7$ & $10.4 \pm 1.1$ & $17.6 \pm 2.7$ & $1.1 \pm 0.2$ & $2.9 \pm 0.7$ & $0.01 \pm 0.0$ & $0.07 \pm 0.0$ \\
\hline 4 & $\begin{array}{c}\mathrm{AOM}+1 \% \mathrm{CPO} \\
(8)\end{array}$ & $22.9 \pm 1.0$ & $4.5 \pm 0.2$ & $14.6 \pm 0.8$ & $12.6 \pm 1.5$ & $5.3 \pm 0.7$ & $11.3 \pm 0.1$ & $17.0 \pm 1.1$ & $1.1 \pm 0.2$ & $3.0 \pm 0.1$ & N.D. & $0.52 \pm 0.1$ \\
\hline 5 & $\begin{array}{c}1 \% \mathrm{CPO} \\
\text { (4) }\end{array}$ & $25.3 \pm 1.3$ & $5.3 \pm 0.7$ & $13.4 \pm 0.9$ & $16.2 \pm 1.5$ & $3.3 \pm 0.2$ & $11.1 \pm 0.6$ & $16.5 \pm 2.0$ & $0.5 \pm 0.2$ & $3.3 \pm 0.3$ & N.D. & $0.04 \pm 0.0$ \\
\hline 6 & $\begin{array}{c}\text { No treatment } \\
\text { (4) }\end{array}$ & $26.9 \pm 1.2$ & $6.7 \pm 0.7$ & $12.2 \pm 1.4$ & $19.4 \pm 2.1$ & $3.4 \pm 0.3$ & $9.4 \pm 0.2$ & $15.0 \pm 2.0$ & $0.5 \pm 0.1$ & $2.8 \pm 0.4$ & N.D. & N.D. \\
\hline
\end{tabular}

aMean \pm SD. N.D., not detected.

Table V. Effect of CPO diets on fatty acid composition of colonic mucosa.

\begin{tabular}{|c|c|c|c|c|c|c|c|c|c|c|c|}
\hline \multirow{2}{*}{$\begin{array}{l}\text { Group } \\
\text { no. }\end{array}$} & \multirow{2}{*}{$\begin{array}{c}\text { Treatment } \\
\text { (no. of rats examined) }\end{array}$} & \multicolumn{10}{|c|}{ Fatty acid (wt $\%)$} \\
\hline & & $14: 0$ & $16: 0$ & $16: 1 \mathrm{n}-7$ & 18:0 & $18: 1 \mathrm{n}-9$ & $18: 1 \mathrm{n}-7$ & $18: 2 n-6$ & $20: 4 n-6$ & $9 c, 11 t$-CLA & $9 t, 11 t$-CLA \\
\hline 1 & AOM alone (5) & $1.5 \pm 0.0^{\mathrm{a}}$ & $28.3 \pm 1.2$ & $8.9 \pm 1.2$ & $3.1 \pm 0.5$ & $28.0 \pm 0.6$ & $4.0 \pm 0.3$ & $21.0 \pm 0.4$ & $1.3 \pm 0.8$ & $0.08 \pm 0.0$ & $0.09 \pm 0.0$ \\
\hline 2 & $\mathrm{AOM}+0.01 \% \mathrm{CPO}(5)$ & $1.4 \pm 0.0$ & $30.0 \pm 0.3$ & $9.1 \pm 0.3$ & $3.3 \pm 0.5$ & $29.3 \pm 0.8$ & $3.7 \pm 0.1$ & $18.4 \pm 0.8$ & $1.0 \pm 0.7$ & $0.06 \pm 0.0$ & $0.11 \pm 0.0$ \\
\hline 3 & $\mathrm{AOM}+0.1 \% \mathrm{CPO}(5)$ & $1.4 \pm 0.0$ & $29.2 \pm 0.9$ & $9.6 \pm 0.9$ & $3.5 \pm 0.5$ & $27.7 \pm 0.7$ & $3.8 \pm 0.3$ & $18.4 \pm 1.5$ & $1.6 \pm 0.6$ & $0.06 \pm 0.0$ & $0.30 \pm 0.0$ \\
\hline 4 & $\mathrm{AOM}+1 \% \mathrm{CPO}(5)$ & $1.5 \pm 0.0$ & $28.9 \pm 1.1$ & $9.9 \pm 1.1$ & $2.9 \pm 0.3$ & $26.2 \pm 0.4$ & $3.7 \pm 0.0$ & $18.8 \pm 1.2$ & $1.2 \pm 0.4$ & $0.09 \pm 0.0$ & $2.29 \pm 0.2$ \\
\hline 5 & $1 \% \mathrm{CPO}(2)$ & $1.5 \pm 0.1$ & $30.2 \pm 0.6$ & $10.5 \pm 0.6$ & $2.7 \pm 0.2$ & $26.8 \pm 0.3$ & $3.7 \pm 0.2$ & $18.1 \pm 0.7$ & $0.8 \pm 0.4$ & $0.09 \pm 0.0$ & $2.44 \pm 0.3$ \\
\hline 6 & No treatment (2) & $1.6 \pm 0.0$ & $31.1 \pm 0.3$ & $10.1 \pm 0.3$ & $3.2 \pm 0.1$ & $29.6 \pm 0.3$ & $3.4 \pm 0.1$ & $17.4 \pm 0.9$ & $1.0 \pm 0.1$ & $0.07 \pm 0.0$ & $0.09 \pm 0.0$ \\
\hline
\end{tabular}

a Mean \pm SD.

(group 2, 32 $\pm 11, \mathrm{P}<0.001$ ), $0.1 \%$ (group 3, 35 $\pm 18, \mathrm{P}<0.001$ ), and $1 \%$ (group $4,18 \pm 10, \mathrm{P}<0.001$ ) $\mathrm{CPO}$ significantly reduced the number of ACF: $68 \%$ inhibition in group 2,65\% inhibition in group 3 , and $82 \%$ inhibition in group 4 . Furthermore, significant decreases were found in the number of aberrant crypts (ACs) per colon $(\mathrm{P}<0.001)$ and the number of $\mathrm{ACs} /$ focus $(\mathrm{P}<0.001)$ in groups 2 through 4 when compared to those in group 1. Also the percentages of ACF consisting of more than 4 ACs in groups $2(1.25 \pm 2.80, \mathrm{P}<0.001), 3(1.30 \pm 1.78$, $\mathrm{P}<0.001)$, and $4(1.62 \pm 2.25, \mathrm{P}<0.001)$ were significantly smaller than that of group $1(32.13 \pm 4.28)$. In groups 5 and 6 , there was no microscopically observable change, including $\mathrm{ACF}$, in the colonic mucosa.

Lipid analysis. The fatty acid profiles of the lipids from the liver tissue and colonic mucosa are shown in Tables IV and V, respectively. CPO diets contained $\sim 40 \%$ of catalpic acid $(9 t, 11 t, 13 c-\mathrm{CLN})$, however it was not detected in these tissues of rats fed CPO-containing diets at three different doses. On the other hand, the contents of CLA $(9 t, 11 t-18: 2)$ in the same tissues were elevated in a dose-dependent manner. Although the CPO diets contained $>40 \%$ of linoleic acid (LA), the amount of LA in the groups administered the CPO-containing diet was insignificant compared with that in the groups fed the diet without CPO.

Serum concentration of total cholesterol and triglycerides. Serum concentrations of total cholesterol and triglycerides are summarized in Fig. 3. The total cholesterol level in the $\mathrm{AOM}+0.01 \% \mathrm{CPO}$ group $(67.4 \pm 6.0 \mathrm{mg} / \mathrm{dl})$ was lower than that in the AOM alone group $(77.4 \pm 6.2 \mathrm{mg} / \mathrm{dl})$ without statistical significance. Serum triglyceride levels of rats that were fed the $\mathrm{AOM}+\mathrm{CPO}$ diet (the $\mathrm{AOM}+0.01 \% \mathrm{CPO}$ group: $77.2 \pm 18.7 \mathrm{mg} / \mathrm{dl}$; the $\mathrm{AOM}+0.1 \%$ CPO group: $69.0 \pm 12.7 \mathrm{mg} /$ $\mathrm{dl}$; and the AOM + 1\% CPO group: $44.6 \pm 7.6 \mathrm{mg} / \mathrm{dl}$ ) were reduced dose dependently, when compared to the AOM alone group $(94.6 \pm 4.0 \mathrm{mg} / \mathrm{dl})$. A significant difference $(\mathrm{P}<0.05)$ was detected between the $\mathrm{AOM}+1 \% \mathrm{CPO}$ and $\mathrm{AOM}$ alone group. Expression of COX-2 mRNA levels in colonic mucosa. As illustrated in Fig. 4, expression of COX-2 mRNA level was 


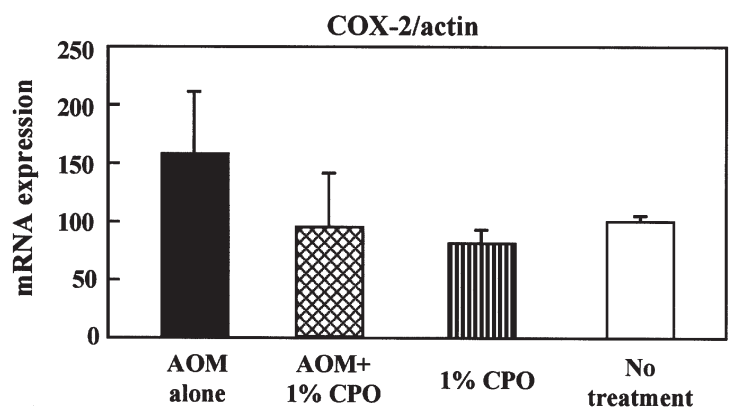

Figure 4. Effect of CPO diet on COX-2 mRNA expression in rat colon mucosa.

Table VI. PCNA and apoptosis indices in rat colonic mucosa.

\begin{tabular}{llcc}
\hline $\begin{array}{l}\text { Group } \\
\text { no. }\end{array}$ & $\begin{array}{c}\text { Treatment } \\
\text { (no. of rats examined) }\end{array}$ & $\begin{array}{c}\text { PCNA-labeling } \\
\text { index (\%) }\end{array}$ & $\begin{array}{c}\text { Apoptotic index } \\
(\%)\end{array}$ \\
\hline 1 & AOM alone (5) & $24.6 \pm 5.6^{\mathrm{a}}$ & $3.8 \pm 0.8$ \\
2 & $\mathrm{AOM}+0.01 \%$ CPO (5) & $18.8 \pm 4.1$ & $5.4 \pm 2.3$ \\
3 & $\mathrm{AOM}+0.1 \% \mathrm{CPO}(5)$ & $17.4 \pm 2.9$ & $6.8 \pm 1.5$ \\
4 & $\mathrm{AOM}+1 \% \mathrm{CPO}(5)$ & $15.2 \pm 3.2^{\mathrm{b}}$ & $8.2 \pm 1.3^{\mathrm{c}}$
\end{tabular}

${ }^{\mathrm{a}}$ Mean $\pm \mathrm{SD}$. ${ }^{\mathrm{b}, \mathrm{c}}$ Significantly different from group 1 by Bonferroni Multiple Comparisons test $\left({ }^{\mathrm{b}} \mathrm{P}<0.05\right.$ and $\left.{ }^{\mathrm{C}} \mathrm{P}<0.01\right)$.

up-regulated by $\sim 1.5$-fold in the colonic mucosa of the AOM alone group when compared with the untreated group (group 6). On the other hand, rats that received AOM and CPO-containing diet showed a low expression level of COX-2 mRNA.

Immunohistochemistry for PCNA and SSDNA in colonic mисоsa. As summarized in Table VI, the PCNA-labeling index of colonic mucosa in groups 2 (18.8 \pm 4.1$), 3(17.4 \pm 2.9)$, and 4 (15.2 \pm 3.2$)$ was smaller than that in group $1(24.6 \pm 5.6)$. Apoptotic index measured by ssDNA immunohistochemistry in groups $2(5.4 \pm 2.3), 3(6.8 \pm 1.5)$, and $4(8.2 \pm 1.3)$ was greater than in group $1(3.8 \pm 0.8)$. For both PCNA-labeling index $(\mathrm{P}<0.05)$ and apoptotic index $(\mathrm{P}<0.01)$, statistically significant differences were found in group 4.

\section{Discussion}

The results described here clearly indicate that dietary administration with $\mathrm{CPO}$ that contains a large amount of catalpic acid $(9 t, 11 t, 13 c-\mathrm{CLN})$ significantly reduced AOMinduced rat $\mathrm{ACF}$ formation at any dose level $(0.01 \%, 0.1 \%$, or $1 \%$ ) as compared with the rats injected with $\mathrm{AOM}$ alone. Also, animals fed the diets containing CPO showed no adverse effects on food intake or growth rate and no histological alterations in any organs. These findings may suggest that dietary CPO suppresses the early phase of chemically-induced colon carcinogenesis. Previously we reported that dietary administration with $9 c, 11 t, 13 t$-CLN caused a significant reduction in the frequency of $\mathrm{ACF}$ (19\% reduction by $0.01 \%$ $9 c, 11 t, 13 t$-CLN, $36 \%$ reduction by $0.1 \% 9 c, 11 t, 13 t$-CLN, and $63.0 \%$ reduction by $1 \% 9 c, 11 t, 13 t$-CLN) (20). In the present study, the inhibition rates of the total number of ACF at 0.01 , 0.1 , and $1 \%$ CPO were 68,65 , and $82 \%$, respectively. This may suggest that the distinction of geometric isomers of CLN might have an explanation for such differences of inhibition rate. Despite CPO containing a significant amount of LA that influences colorectal cancer (5), colonic ACF was suppressed by CPO. Our findings may suggest that $t 9, t 11, c 13-18: 3$ in $\mathrm{CPO}$ is a good natural chemopreventive agent against colon carcinogenesis.

COX enzymes play a central role in the conversion of arachidonic acid (AA) to prostaglandins. One of the COX-2 reaction products, PGE2, is known to lead to the induction of cell proliferation and the inhibition of apoptosis which favor tumor development $(23,26)$. Suppression of the enzyme COX is suggested to be the potential mechanism for inhibition of carcinogenesis. In colon carcinogenesis, overexpression of COX-2 was observed in ACF, adenomas, and adenocarcinomas (32), suggesting that the overexpression of COX-2 contributes to the growth of precursor lesions and tumors and their progression. In fact, treatment with the selective COX-2 inhibitor celecoxib gave us promising results in the prevention of colorectal cancer (26). Also Rao et al (24) demonstrated that celecoxib significantly reduced AOM-induced rat colon ACF. In the current study, dietary administration with $\mathrm{CPO}$ reduced COX-2 mRNA expression in the colonic mucosa, and this may account for lowering the number of colonic ACF. Since CLA causes down-regulation of COX-2 activity (33), accumulated CLA in the colonic mucosa might also contribute to reducing the expression of COX-2 mRNA.

In the current study, dietary administration with CPO decreased cell proliferation activity and increased apoptosis index in the AOM-induced rat colonic mucosa. Also, downexpression of anti-apoptosis protein, bcl-xL, was found in the colonic mucosa of rats treated with $\mathrm{AOM}$ and $\mathrm{CPO}$ (data not shown). Previously, we reported that BMO has the ability to decrease the PCNA-labeling index and enhance the apoptosisindex (20). Thus, the inhibitory effect of CPO on ACF might partly be due to modulation of cell proliferation and apoptosis. Since inhibition of COX-2 expression results in resistance to cell proliferation and increased apoptosis $(23,26)$, the reduction of COX-2 mRNA expression in the present study might contribute to the modulation effect of $\mathrm{CPO}$ on cell proliferation and apoptosis.

We found a dose-dependent accumulation of t9,t11-18:2 in the colonic mucosa and liver tissue of rats that were fed CPO. Also the contents of $c 9, t 11-18: 2$ in the colonic mucosa and liver tissue of rats given PGO that contained over $70 \%$ of $c 9, t 11, \mathrm{c} 13-18: 3$ were elevated in a dose-dependent manner (12). Others reported that CLA generated in rats after $c 9, t 11, t 13-18: 3$ administration was confirmed to be $c 9, t 11$ 18:2 (34). We speculated that $t 9, t 11, c 13-18: 3$ rich in CPO was saturated at the $\Delta 13$ position and converted to $t 9, t 11$ 18:2 in the current study. We and others reported that CLA inhibits the occurrence of chemically-induced colonic ACF (35) and tumor (12) in rats. Also t9,t11-18:2 can suppress the growth of human cancer cells (36). Therefore, $t 9, t 11-18: 2$ 
converted from $t 9, t 11, c 13-18: 3$ might contribute to prevention of the development of colonic preneoplasms in the present study. CPO contains $\sim 40 \%$ LA besides catalpic acid. After intake of LA, it can be oxidized, stored in triacylglycerides, incorporated into membranous phospholipids, or elongated and desaturated to more unsaturated fatty acids such as $\gamma$-linolenic acid (LN), dihomo- $\gamma$ - LN, and AA. Excess of n-6 PUFA consumption is one of the causes of colorectal cancer development (5). Administration of an LAenriched diet also enhanced chemically-induced rat $\mathrm{ACF}$ occurrence and multiplicity (37). In the current study, the amounts of LA and AA of colonic mucosa and liver lipids in groups 2 through 4 did not significantly differ from those in group 1 . These modifying effects of CPO on fatty acid profile in colonic mucosa or liver lipid might partly influence its inhibitory ability in ACF formation.

Serum levels of triglycerides and cholesterol have been shown to be positively associated with colon carcinogenesis $(38,39)$. Niho et al found that serum levels of triglycerides in Min mice are dramatically increased compared to the wild-type and the increase contributes to the growth of small intestinal polyps (40). They also demonstrated that a peroxisome proliferator-activated receptors (PPAR) $\gamma$ ligand suppresses both serum triglyceride level and intestinal polyp formation in Min mice (40). A synthetic ligand for PPAR $\gamma$ can inhibit AOM-induced rat colonic ACF (41) and colitis-related mouse colon cancer development (42). These findings suggest that activation of PPAR $\gamma$ is beneficial for colon cancer prevention. Since BMO containing $c 9, t 11, t 13-18: 3$ and PGO rich in $c 9, t 11, c 13-18: 3$ can up-regulate PPAR $\gamma(12,43)$, CPO might be a natural ligand of PPAR $\gamma$. Feeding with CLA also increases the expression of PPAR $\gamma$ protein as compared to the basal diet (12). Since oxidative metabolites of LA, including 13hydroxyoctadecadienoic acid and 13-oxooctadecadienoic acid are reported to activate PPAR $\gamma$ (44), it may be possible that accumulated CLA or linoleate metabolites activated PPAR $\gamma$ in this study. Although we did not determine PPAR $\gamma$ expression in the colon, possible modulatory effects of CPO may partly contribute to its inhibitory effect on ACF occurrence.

In conclusion, the findings described here demonstrate for the first time that dietary administration of CPO rich in catalpic acid $(9 t, 11 t, 13 c$-CLN) significantly inhibited the development of AOM-induced ACF in rats. Although the exact mechanisms by which CPO inhibits colonic early preneoplastic lesions remain to be elucidated, it would be worthwhile to test the cancer chemoprevention ability of CPO using a long-term colon carcinogenesis model.

\section{Acknowledgements}

We express our thanks to the staff of the Research Animal Facility, Kanazawa Medical University. This study was supported by the Grant-in-Aid for Cancer Research from the Ministry of Health, Labour and Welfare of Japan; the Grantin-Aid for the 3rd Term for a Comprehensive 10-year Strategy for Cancer Control from the Ministry of Health, Labour and Welfare of Japan; the Grants-in-Aid for Scientific Research (nos. 15.205200/20029 and 18592076) from the Ministry of Education, Culture, Sports, Science and Technology of
Japan; and grants (H2005-6 and C2005-3) from Kanazawa Medical University.

\section{References}

1. Jemal A, Murray T, Ward E, et al: Cancer statistics, 2005. CA Cancer J Clin 55: 10-30, 2005.

2. Kono S: Secular trend of colon cancer incidence and mortality in relation to fat and meat intake in Japan. Eur J Cancer Prev 13: 127-132, 2004.

3. Roynette CE, Calder PC, Dupertuis YM and Pichard C: n-3 polyunsaturated fatty acids and colon cancer prevention. Clin Nutr 23: 139-151, 2004.

4. Nkondjock A, Shatenstein B, Maisonneuve P and Ghadirian P: Specific fatty acids and human colorectal cancer: an overview. Cancer Detect Prev 27: 55-66, 2003.

5. Bougnoux $P$ and Menanteau J: Dietary fatty acids and experimental carcinogenesis. Bull Cancer 92: 685-696, 2005.

6. Nagao $\mathrm{K}$ and Yanagita T: Conjugated fatty acids in food and their health benefits. J Biosci Bioeng 100: 152-157, 2005.

7. Kelly GS: Conjugated linoleic acid: a review. Altern Med Rev 6: 367-382, 2001 .

8. Belury MA: Dietary conjugated linoleic acid in health: physiological effects and mechanisms of action. Annu Rev Nutr 22: 505-531, 2002.

9. Belury MA, Nickel KP, Bird CE and Wu Y: Dietary conjugated linoleic acid modulation of phorbol ester skin tumor promotion. Nutr Cancer 26: 149-157, 1996.

10. Futakuchi M, Cheng JL, Hirose M, et al: Inhibition of conjugated fatty acids derived from safflower or perilla oil of induction and development of mammary tumors in rats induced by 2-amino-1methyl-6-phenylimidazo[4,5- $b$ ]pyridine (PhIP). Cancer Lett 178: 131-139, 2002.

11. Ha YL, Storkson J and Pariza MW: Inhibition of benzo(a)pyreneinduced mouse forestomach neoplasia by conjugated dienoic derivatives of linoleic acid. Cancer Res 50: 1097-1101, 1990.

12. Kohno H, Suzuki R, Yasui Y, Hosokawa M, Miyashita K and Tanaka T: Pomegranate seed oil rich in conjugated linolenic acid suppresses chemically induced colon carcinogenesis in rats. Cancer Sci 95: 481-486, 2004.

13. Lin H, Boylston TD, Chang MJ, Luedecke LO and Shultz TD: Survey of the conjugated linoleic acid contents of dairy products. J Dairy Sci 78: 2358-2365, 1995.

14. Takagi T and Itabashi Y: Occurrence of mixtures of geometrical isomers of conjugated octadecatrienoic acids in some seed oils: analysis by open-tubular gas liquid chromatography and high performance liquid chromatography. Lipids 16: 546-551, 1981.

15. Koba K, Akahoshi A, Yamasaki M, et al: Dietary conjugated linolenic acid in relation to CLA differently modifies body fat mass and serum and liver lipid levels in rats. Lipids 37: 343-350, 2002.

16. Arao K, Yotsumoto H, Han SY, Nagao K and Yanagita T: The 9 cis, 11 trans, 13 cis isomer of conjugated linolenic acid reduces apolipoprotein B100 secretion and triacylglycerol synthesis in HepG2 cells. Biosci Biotechnol Biochem 68: 2643-2645, 2004.

17. Arao K, Wang YM, Inoue N, et al: Dietary effect of pomegranate seed oil rich in 9cis, 11 trans, 13cis conjugated linolenic acid on lipid metabolism in obese, hyperlipidemic OLETF rats. Lipids Health Dis 3: 24, 2004.

18. Suzuki R, Noguchi R, Ota T, Abe M, Miyashita K and Kawada T: Cytotoxic effect of conjugated trienoic fatty acids on mouse tumor and human monocytic leukemia cells. Lipids 36: 477-482, 2001 .

19. Igarashi M and Miyazawa T: Newly recognized cytotoxic effect of conjugated trienoic fatty acids on cultured human tumor cells. Cancer Lett 148: 173-179, 2000.

20. Kohno H, Suzuki R, Noguchi R, Hosokawa M, Miyashita K and Tanaka T: Dietary conjugated linolenic acid inhibits azoxymethane-induced colonic aberrant crypt foci in rats. Jpn J Cancer Res 93: 133-142, 2002.

21. Bird RP and Good CK: The significance of aberrant crypt foci in understanding the pathogenesis of colon cancer. Toxicol Lett 112-113: 395-402, 2000 .

22. Kohno H, Yasui Y, Suzuki R, Hosokawa M, Miyashita K and Tanaka T: Dietary seed oil rich in conjugated linolenic acid from bitter melon inhibits azoxymethane-induced rat colon carcinogenesis through elevation of colonic PPAR $\gamma$ expression and alteration of lipid composition. Int J Cancer 110: 896-901, 2004. 
23. Wendum D, Masliah J, Trugnan G and Flejou JF: Cyclooxygenase- 2 and its role in colorectal cancer development. Virchows Arch 445: 327-333, 2004.

24. Rao CV, Indranie C, Simi B, Manning PT, Connor JR and Reddy BS: Chemopreventive properties of a selective inducible nitric oxide synthase inhibitor in colon carcinogenesis, administered alone or in combination with celecoxib, a selective cyclooxygenase-2 inhibitor. Cancer Res 62: 165-170, 2002.

25. Takahashi M and Wakabayashi K: Gene mutations and altered gene expression in azoxymethane-induced colon carcinogenesis in rodents. Cancer Sci 95: 475-480, 2004.

26. Koehne CH and Dubois RN: COX-2 inhibition and colorectal cancer. Semin Oncol 31 (2 Suppl 7): 12-21, 2004.

27. Suzuki R, Kohno H, Sugie S, et al: Preventive effects of extract of leaves of ginkgo (Ginkgo biloba) and its component bilobalide on azoxymethane-induced colonic aberrant crypt foci in rats. Cancer Lett 210: 159-169, 2004.

28. Folch J, Lees M and Sloane Stanley GH: A simple method for the isolation and purification of total lipides from animal tissues. J Biol Chem 226: 497-509, 1957.

29. Prevot AF and Moderet FX: Utilisation des colonnes capillaries de verre pur l'analyse des corps gras par chromatographie en phase gazeuse. Rev Fse Corps Gras 23: 409-423, 1976.

30. Sehat N, Kramer JK, Mossoba MM, et al: Identification of conjugated linoleic acid isomers in cheese by gas chromatography, silver ion high performance liquid chromatography and mass spectral reconstructed ion profiles. Comparison of chromatographic elution sequences. Lipids 33: 963-971, 1998.

31. Watanabe I, Toyoda M, Okuda J, et al: Detection of apoptotic cells in human colorectal cancer by two different in situ methods: antibody against single-stranded DNA and terminal deoxynucleotidyl transferase-mediated dUTP-biotin nick endlabeling (TUNEL) methods. Jpn J Cancer Res: 188-193, 1999.

32. Takahashi M, Mutoh M, Kawamori T, Sugimura T and Wakabayashi K: Altered expression of B-catenin, inducible nitric oxide synthase and cyclooxygenase- 2 in azoxymethaneinduced rat colon carcinogenesis. Carcinogenesis 21: 1319-1327, 2000.

33. Watkins BA and Seifert MF: Conjugated linoleic acid and bone biology. J Am Coll Nutr 19: 478S-486S, 2000.
34. Tsuzuki T, Tokuyama Y, Igarashi $\mathrm{M}$, et al: $\alpha$-Eleostearic acid (9Z11E13E-18:3) is quickly converted to conjugated linoleic acid (9Z11E-18:2) in rats. J Nutr 134: 2634-2639, 2004.

35. Liew C, Schut HA, Chin SF, Pariza MW and Dashwood RH: Protection of conjugated linoleic acids against 2-amino-3methylimidazo[4,5-f]quinoline-induced colon carcinogenesis in the F344 rat: a study of inhibitory mechanisms. Carcinogenesis 16: 3037-3043, 1995

36. De la Torre A, Debiton E, Durand D, et al: Conjugated linoleic acid isomers and their conjugated derivatives inhibit growth of human cancer cell lines. Anticancer Res 25: 3943-3949, 2005.

37. Delage B, Groubet R, Pallet V, Bairras C, Higueret P and Cassand P: Vitamin A prevents high fat diet-induced ACF development and modifies the pattern of expression of peroxisome proliferator and retinoic acid receptor m-RNA. Nutr Cancer 48: 28-36, 2004.

38. McKeown-Eyssen G: Epidemiology of colorectal cancer revisited: are serum triglycerides and/or plasma glucose associated with risk? Cancer Epidemiol Biomarkers Prev 3: 687-695, 1994.

39. Yamada K, Araki S, Tamura M, et al: Relation of serum total cholesterol, serum triglycerides and fasting plasma glucose to colorectal carcinoma in situ. Int J Epidemiol 27: 794-798, 1998.

40. Niho N, Takahashi M, Shoji Y, et al: Dose-dependent suppression of hyperlipidemia and intestinal polyp formation in Min mice by pioglitazone, a PPAR $\gamma$ ligand. Cancer Sci 94: 960-964, 2003.

41. Kohno H, Yoshitani S, Takashima S, et al: Troglitazone, a ligand for peroxisome proliferator-activated receptor $\gamma$, inhibits chemically-induced aberrant crypt foci in rats. Jpn J Cancer Res 92: 396-403, 2001.

42. Kohno H, Suzuki R, Sugie S and Tanaka T: Suppression of colitis-related mouse colon carcinogenesis by a COX-2 inhibitor and PPAR ligands. BMC Cancer 5: 46, 2005.

43. Yasui Y, Hosokawa M, Sahara T, et al: Bitter gourd seed fatty acid rich in $9 c, 11 t, 13 t$-conjugated linolenic acid induces apoptosis and up-regulates the GADD45, p53 and PPAR $\gamma$ in human colon cancer Caco-2 cells. Prostaglandins Leukot Essent Fatty Acids 73: 113-119, 2005.

44. Nagy L, Tontonoz P, Alvarez JG, Chen H and Evans RM: Oxidized LDL regulates macrophage gene expression through ligand activation of PPAR $\gamma$. Cell 93: 229-240, 1998. 